\title{
1 Could Social Robots Make Us Kinder or Crueller to Humans
}

2 and Animals?

\author{
3 Simon Coghlan ${ }^{1}\left[\right.$ [ $\cdot$ Frank Vetere $^{1} \cdot$ Jenny Waycott ${ }^{1} \cdot$ Barbara Barbosa Neves $^{2}$
}

Accepted: 22 August 2019

(c) Springer Nature B.V. 2019

\begin{abstract}
The Montréal Declaration for Responsible Development of Artificial Intelligence states that emerging technologies ought not "encourage cruel behaviour towards robots that take on the appearance of human beings or animals and act in a similar fashion." The idea of a causal link between cruelty and kindness to artificial and living beings, human or animal, is contro- $\mathbf{A Q 2}$ versial and underexplored, despite its increasing relevance to robotics. Kate Darling recently marshalled Immanuel Kant's argument - that cruelty to animals promotes cruelty to people — to argue for an analogous link concerning social robots. Others, such as Johnson and Verdicchio, have counter-argued that animal analogies are often flawed, partly because they ignore social robots' true nature, including their lack of sentience. This, they say, weakens Darling's argument that social $\mathbf{A Q 3}$ robots will have virtue-promoting or vice-promoting effects regarding our treatment of living beings. Certain ideas in this debate, including those of anthropomorphism, projection, animal analogies, and Kant's causal claim, require clarification $\mathbf{A Q 4}$ and critical attention. Concentrating on robot animals, this paper examines strengths and weaknesses on both sides of this argument. It finds there is some reason for thinking that social robots may causally affect virtue, especially in terms of the $\mathbf{A 0 5}$ moral development of children and responses to nonhuman animals. This conclusion has implications for future robot design and interaction.
\end{abstract}

Keywords Social robots $\cdot$ Companion robots $\cdot$ Animals $\cdot$ Moral virtue $\cdot$ Anthropomorphism $\cdot$ Children

\section{Introduction}

The 2016 Montréal Declaration for Responsible Development of Artificial Intelligence states that emerging technologies "shouldn't encourage cruel behaviour towards robots that take on the appearance of human beings or animals and act in a similar fashion" [1]. This statement raises several ethical questions regarding human behaviours or responses (actions, attitudes, feelings) to social robots. These include:

1. Do/will social robots have intrinsic moral standing, such that they can be wronged or owed direct duties as moral patients? [2-6]

Simon Coghlan

simon.coghlan@unimelb.edu.au

1 Computing and Information Systems, Melbourne School of Engineering, The University of Melbourne, Parkville, VIC 3010, Australia

2 School of Social and Political Sciences, Faculty of Arts, The University of Melbourne, Parkville, VIC 3010, Australia
2. Even if robots lack intrinsic moral standing or patiency, could certain responses to them nevertheless intrinsically constitute unethical or unvirtuous responses? [7]

3. Could certain responses to social robots causally promote good or bad responses to sentient beings and so shape virtue and vice in relation to those beings, human or animal? [8]

We shall mostly assume that robots do not and will not have intrinsic moral standing (question 1) (but see Sect. 9). We think it possible that actions such as "torturing" a robot could be intrinsically unethical or unvirtuous (question 2). However, question 3 is our focus. We shall speak herein of a "social robot-human virtue link." This "link" refers to the possibility that responses to social robots may, for better or worse, causally influence human responses towards living beings (human or animal)—responses which partly constitute human virtue and vice.

Question 3 has generated recent scholarly disagreement. Cappuccio et al. [8] analyse the virtue-shaping potential of robots in terms of social recognition theory. Darling [9]

\begin{tabular}{|l|l|l|l|l|}
\hline Journal : Large 12369 & Article No : 583 & Pages : 11 & MS Code : 583 & Dispatch : 24-8-2019 \\
\hline
\end{tabular}


also argues that abusing humanoid and animal robots might causally precipitate bad behaviour towards sentient animals and people. Like Anderson [10] before her, Darling invokes Immanuel Kant's [11] famous claim that hardness (or tenderness) to animals engenders hardness (or tenderness) to humans. She suggests we may need laws protecting anthropomorphic/zoomorphic robots that resemble animal cruelty laws. Calo [12, p 549] suggests "a new category of legal subject, halfway between person and object" may become necessary for social robots.

Others are less sure. Coeckelbergh [13] notes the insufficient empirical evidence concerning a "link." Black [14] suggests that humanoid robots, and in particular their faces, might need to be (almost) indistinguishable from humans in order for their mistreatment to engender callousness or cruelty to people. In a more sceptical vein, Johnson and Verdicchio [15] contend, in a paper called "Why robots should not be treated like animals," that trading in animal analogies in the way Darling does can be misleading. They argue that while animals are capable of genuine perception, feeling, and suffering, robots merely simulate sentience, and that this key fact renders dubious any putative causal chain linking human-robot interaction and ethical responses to sentient beings.

Although other writers have explored robot anthropomorphism/zoomorphism and some of its social implications [16, 17], we shall concentrate on Darling's and Johnson/Verdicchio's disagreement, since it displays clearly and in detail certain questions, especially conceptual questions, which we believe require illumination. These include the questions of anthropomorphism, projection, animal analogies, and Kant's causal claim. Both "sides" of this disagreement, we believe, may mislead us in various ways about the alleged "link." A conceptual investigation of the putative "link" is also useful because, as we explain below, empirical support for a robot link is suggestive but inconclusive (Sects. 2, 5).

Nevertheless, we offer some qualified support for the plausibility of a social robot-human virtue link: Social robots may influence the development of moral virtue or vice in relation to responses to living beings. A link is most plausible, we will argue, when it is understood in terms of effects on children, and on ethical attitudes and behaviour towards nonhuman animals. We do, however, acknowledge the possibility that social robots could influence adult moral responses to both humans and animals.

Our discussion borrows from virtue ethics/theory [18, 19]. Virtues are character traits constituted by a range of feelings, actions, attitudes, cognitions, and emotions. Examples of virtues include compassion and kindness. Vices, by contrast, include traits like callousness and cruelty. Like Cappuccio et al. [8], we will use some of virtue theory's insights into moral psychology and behaviour without siding with virtue ethics as a normative theory. For example, virtue theory determines right action not as (say) deontology does [20], namely by reference to moral rules, but rather by asking what a morally exemplary person of virtue would do in a particular situation. In this essay, we remain agnostic on this and some other (but not all) claims in virtue theory. Nor do we side with any other moral theory.

Even non-virtue ethicists may regard virtues as important. For example, we may think that virtues like kindness engender social harmony. We may also think that virtues promote personal wellbeing or contentment. Some (certainly not all) people may even claim, like Aristotle [21], that virtues do not merely causally promote personal wellbeing, but that virtues also constitutively benefit their possessors-and that corrupting vices like cruelty constitutively harm them. Virtue arguably connects with our behavior towards animals as well as humans. Indeed, the intrinsic moral standing of animals is increasingly recognized [22-24]. For a variety of reasons, then, we may be interested in promoting virtuous responses (like kindness or compassion) and discouraging unvirtuous responses (like callousness and cruelty), towards both humans and animals.

Many popular companion robots, like Paro (seal), Pleo (dinosaur), and AIBO (dog) are animal-like (zoomorphic). Some human-looking robots appear to raise unmet expectations and trigger uncanny valley-style push-back [25-27]. Potentially, future social robots may blend elements of both human and animal appearance and/or behaviour [28]. Our paper frequently considers animal-like robots, although the discussion is often applicable to humanoid robots too.

\section{Empirical Evidence and the Social Robot- Human Virtue Link}

Although our investigation is frequently conceptual, empirical evidence is clearly relevant to claims about a "link." In this section, we briefly review some empirical studies that are at least suggestive of a robot link. Social robots are designed to be used in human social (e.g. domestic) settings [29] to simulate human or animal-like appearances and/or behaviours, and to evoke the kinds of responses that humans or nonhuman animals elicit [30]. For example, social robots may be designed to be companions and so to trigger human responses of communication, play, emotion, and care [31, 32].

Humans have surprisingly strong tendencies to display "social" responses to technologies. So-called "media equation" experiments show that people often respond even to computers with politeness and consideration [33]. But responses to robots apparently go further. People may (in some sense) instinctively respect a robot's personal space, trust their judgment, and hold them responsible for their actions [34-36]. Attachment can also apparently occur. 
For example, when a robot security guard named Steve "drowned" in a fountain in Washington, some locals created a memorial [37]. Video showing robots from Boston Dynamics being pushed over when they are trying to complete tasks like lifting objects and walking [38] have prompted unexpected responses. Footage of a four-legged robot stumbling and scrambling to regain balance after being kicked [39] has elicited something like pity and anger at the "callous" human, and a desire to halt the "abuse."

Humans apparently "empathize" with actual robots while empathizing relatively less with simulations [40]. Experiments modelled on Milgram's obedience studies suggest that participants are reluctant to shock robot subjects-less reluctant than for human subjects but more reluctant than for virtual robot representations [41]. Darling tells of a colonel who observed the actions of a six-legged anti-land mine robot, and "could not stand the pathos of watching the burned, scarred and crippled machine drag itself forward on its last leg. This test, he charged, was inhumane" [9, p 217]. Robots also apparently induce affection. Sandry reports that soldiers "bringing in damaged robots for repair do not want to be given a new robot, they want the old one to be fixed" $[29,42]$. Conversely, some studies reveal children verbally abusing, kicking, and punching robots [43]. Such "cruelty" recalls the way children sometimes squash insects, tease or hurt cats, and relish their power over weak or vulnerable creatures [44].

The above sorts of studies suggest that responses to social robots resemble in some ways responses to living beings, human and animal. These responses apparently occur instinctively and irresistibly, despite the fact that robots are "merely" machines. We should note that empirical and conceptual investigation of these responses is relatively young [45]. Further, such responses may intensify as robots become increasingly autonomous ${ }^{1}$ and lifelike. Increasing levels of anthropomorphism, in which robots are perceived to have human-like qualities, may further influence our responses to robots. Some say that anthropomorphism reflects our need for familiarity [46] or is hard-wired [47]. A study that assessed people's responses to different types of robotic partners in a collaborative computer game scenario found that participants "experienced more joy in the interaction and sympathy for the opponent the more the game partner exhibited anthropomorphic features" [48, p 578]. The authors argued that their findings suggest people "implicitly attribute human-like qualities" to nonhuman agents, such as robots [48, p 578].

\footnotetext{
1 We use autonomous [30] here to mean the capacity to self-initiate action and to exhibit agency (relatively) independently of human control, including acts of self-maintenance and self-preservation (cf. a laptop computer).
}

Such fascinating empirical work suggests that robots may shape human moral responses to living beings. Nonetheless, it must be stressed that this is far from certain. Indeed, even future evidence may not conclusively settle the question of a link (see also the discussion of entertainment media [49, 50] in Sect. 5.1) So how to proceed? Without sufficient empirical data (now or perhaps ever), we must rely on our best judgements about human psychology, morality, and robot technology. In addition to empirical considerations, certain conceptual considerations, which inform those "best" judgements, need exploration. For while empirical studies can shed much light on our responses to robots, on their own they cannot fully reveal the nature of such responses. Conceptual reflection is also needed. The following conceptual and empirical investigation focuses on the disagreement between Darling and Johnson/Verdicchio.

\section{Darling's "Animal Analogy" Argument for a Social Robot-Human Virtue Link}

Darling [9] argues that the mistreatment of social robots potentially may cause the mistreatment of humans and animals. Her argument deploys an animal analogy in the form of Immanuel Kant's [11] causal claim that cruelty or kindness to animals causes, respectively, cruelty or kindness to humans. ${ }^{2}$ Darling argues that granting robots legal protection, similar to animal legal protections, may similarly prevent human "desensitization towards actual living creatures and protect the empathy we have for each other" [9, p 228].

Darling claims that Kant's argument "logically extends" to our treatment of companion robots:

People are prone to anthropomorphism, that is, we project our own inherent qualities onto other entities to make them seem more human-like. Our well-documented inclination to anthropomorphically relate to animals translates remarkably well to robots [9, p 214] ...violent behavior towards robotic objects feels wrong to many of us, even if we know that the "abused" object does not experience anything. We may be hardwired to respond instinctively to cues like simulated pain or need [9, p 223].

So, anthropomorphism and zoomorphism, on Darling's view, involve the projection of human or animal qualities, like pain and distress, onto social robots. This enables empathy towards non-sentient things. The projective act occurs

\footnotetext{
2 Although Kant's claim here relates to the development of virtue/ vice, Kant himself was clearly not a virtue ethicist. Nor are the details of his deontological position particularly relevant for Darling (or us), other than what bears on his causal claim about the effects of cruelty/ kindness to animals.
}

\begin{tabular}{|l|l|l|l|l|}
\hline Journal : Large 12369 & Article No : 583 & Pages : 11 & MS Code : 583 & Dispatch : 24-8-2019 \\
\hline
\end{tabular}




\footnotetext{
3FL01 ${ }^{3}$ Actually, some studies [53] suggest slaughter-workers have more 3 FL02 human-directed aggression (and less empathy for animals). However, $3 \mathrm{FL} 03$ Johnson and Verdicchio may argue that these studies are not conclu3 FL04 sive.

4FL01 ${ }^{4}$ Note that Johnson and Verdicchio do acknowledge that the carryo4 FL02 ver effects of violent films and the like remains an "unresolved issue" $4 \mathrm{FL} 03$ [15, p 299].
}

the remarkable "autonomy" of robots is distinguishable from human (and perhaps animal) autonomy-only the latter involve sentience or consciousness [54].

Johnson and Verdicchio believe that such misunderstandings create unreasonable anxiety about artificial intelligence. Such anxiety abstracts from social contexts, ignoring the "institutions and social arrangements that give AI its capacity to do or mean anything" [54, p 2268]. This context shapes responses to robots. For example (we might say), society may powerfully reinforce a clear-cut ethical difference between robots and humans/animals which effectively counters any virtue/vice-shaping potential of the robots themselves (Sect. 8). In sum, "responsible discourse on robots should be cautious in using analogies with animals" [15, p 300].

\section{Further Problematising the Social Robot- Human Virtue Link}

Darling's argument for a social robot-human virtue link is conditional upon responses to robots being similar enough to responses to living beings. Johnson and Verdicchio effectively doubt they are sufficiently similar for the link to work. This doubt can be deepened. Hence, before we argue that a social robot-human virtue link is plausible, we must note several further obstacles that argument faces.

\subsection{Problems with Inconclusive Empirical Support from Entertainment Media}

It may be argued that studies on the psychosocial effects of entertainment media give credence to a robot "link." However, despite public concern about entertainment mediaincluding violent movies and VR games [55]—contemporary research shows a complex picture. This picture rejects simple cause-effect perspectives that position the individual as a passive receiver of content, incapable of distinguishing between fiction and reality [56]. Indeed, research on the relationship between video games and decreased prosocial behaviour, including aggression or bullying, has shown inconclusive or limited effects $[55,56]$. While most literature focuses on young adults and adults, there is growingbut still scarce-research on children $[56,57]$.

A recent study with British children investigated the relationship between violent games and diverse behaviours, including antisocial attitudes, aggression or bullying, civic attitudes and behaviour [56]. Results demonstrated no significant correlation between violent game exposure and either civic or antisocial behaviours or attitudes [56]. The authors also emphasised the need to further explore how children play and why, particularly considering different motivations, level of engagement, and contexts [56]. In fact, a 
longitudinal study with Japanese children and violent video games had previously highlighted the significance of contexts of play rather than quantity of violence [57].

This last thought recalls Johnson and Verdicchio's suggestion [54] that social context may render some concerns about the ethico-social effects of "cruelty" to robots unwarranted. We should also note, however, the possibility that the social context surrounding certain uses of technologies, such as robots, may potentially encourage worrying behaviours towards humans/animals. Equally, context could promote ethically desirable responses (we return to the matter of social context in Sect. 8). But the main point here is that existing empirical research concerning the psychosocial effects of entertainment media is inconclusive.

\subsection{Problems with Kant's Causal Claim}

Kant's causal claim [11], while apparently plausible, may be further questioned. Kant contended a linear causal link: cruelty (or kindness) towards animals causally induces subsequent cruelty (or kindness) towards humans. However, as Arluke [58] suggests, some acts of animal abuse may be forms of "dirty play" that are confined to phases of childhood and are later repudiated by the perpetrators of that abuse. Furthermore, some recent research which supports a connection between animal cruelty and antisocial criminality, does so not much confirm a linear causal connection of the kind Kant imagined, as a connection grounded rather in personality types [59].

This revealing research suggests that many animal abusers who become criminally abusive of humans already have broad antisocial, impulsive, and violent character traits [59]. On this view, while there is merit in intervening with young animal abusers to prevent them subsequently abusing humans, that is because society can then address their antisocial personalities, rather than because the animal abuse itself precipitates violent crimes against humans. Similarly, perhaps cruelty to robots will not causally induce cruelty to living beings. Admittedly - and importantly - the research does not prove that animal cruelty has no tendency to promote human cruelty, but it does create some doubt [59].

Another possible problem stems from the fact that Kant held only human beings (more precisely: rational beings) to have intrinsic moral standing. Non-rational animals, he argued, are mere means to our ends: "mistreatment" does not wrong them [47]. We have duties concerning animalsas indeed we might for a machine-but they are "indirect" rather than "direct" duties. Kant's deeply anthropocentric ethic holds that the only moral reason for being kind to animals is that such behaviour causally influences our humanity towards rational beings, which have intrinsic dignity or worth $[60,61]$.
This arguably creates a puzzle. If I, like Kant, am convinced that animals (unlike humans) are mere means to our ends, why then should there be a causal flow-on effect in my behavior? In other words, why should wantonly harming things I explicitly regard as mere objects make me more likely to wantonly harm beings I believe with equal certainty have inherent dignity or worth? The firm belief that animals simply cannot be wronged, even by violent "abuse," arguably militates against that psychological transference. For I would be perfectly aware that my act of hurting animals is categorically different from hurting people, even if the animals I hurt display pain and distress and cause certain psychological reactions in me. This seemingly renders those two apparently similar behaviours, psychologically and cognitively, very different indeed. Of course, Darling might say that, unlike Kant, we do regard animals as having intrinsic moral standing; but unless we also regarded social robots as intrinsically morally valuable (see Sect. 9), this would not help her case.

We can now mark two relevant features of human moral psychology. First, our morally-relevant responses often discriminate, perhaps subtly but nonetheless clearly, and also in different ways, between objects that are in many respects similar [7]. To return to an earlier example: not only may a slaughter-worker respond to humans and to animals in abattoirs differently, they may well treat other animals very differently. They may typically be kind to other species (e.g. dogs), and/or kind to the same slaughter species (e.g. pigs) when they encounter them outside the abattoir. These differences in response, which obtain despite the similarities between different animals, may partly constitute a slaughterworker's moral value system, even if they are not particularly self-aware or reasoned responses.

Second and relatedly, although we might regard the slaughter-worker as desensitized ${ }^{5}$ to the sight of animal death, suffering, and violence in the workplace, those relatively callous responses may be cognitively and psychologically compartmentalized [62]. Compartmentalization involves quarantining certain attributes or behaviors from our core self-understanding [63]. Accordingly, despite any tendency for callous responses in the slaughter-room to leak into other areas of life, those responses may be moreor-less confined, psychologically/morally speaking, to the abattoir. Similarly, our responses to robots, notwithstanding any tendency for them to spread to humans and animals, may remain psychologically/morally compartmentalized. Therefore, Darling's assertion that Kant's causal claim "logically extends" to robots is contestable, both as a matter

${ }_{5}$ It is a live, if unsettled, question whether routine slaughter-work causally predisposes to mistreatment of other animals and humans.

\begin{tabular}{|l|l|l|l|l|}
\hline Journal : Large 12369 & Article No : 583 & Pages : 11 & MS Code : 583 & Dispatch : 24-8-2019 \\
\hline
\end{tabular}




\footnotetext{
${ }_{6 \mathrm{FL} 01}{ }^{6}$ It is important to stress that empirical studies alone (e.g. see 6FL02 Sect. 2) cannot resolve these conceptual questions.

7FL01 ${ }^{7}$ The word projection is itself perhaps redolent of an act involving 7FL02 misattributed qualities.
}

misattribute (say) sentience to robots and, in some elementary way, mistake appearance for reality [66]. Damiano and Dumouchel [47], for example, argue that the anthropomorphizing of social robots does not typically involve cognitive error or mis-description. Rather, such anthropomorphising, such as when we say that a robot displays an emotion, involves forms of spontaneous response that function "primarily as a tool for interacting [with robots], not a description of the world" [47, p 6]. Złotowski et al. [67, p 347] draw attention to ways that we anthropomorphize without necessarily making false attributions-for instance, we may see human features in weather patterns or refer to "Mother Earth.”

Another suggestion, by Melson et al. [68], is that our responses to certain robots are sui generis responses to a new "ontological category" of being. On this view, we regard robots as neither living nor nonliving, neither sentient nor non-sentient, etc. Accordingly, there is no mistaking robots for sentient beings, human or animal. Certainly, this view involves seeing robots as very human-like or animal-like. Nonetheless, it entails that we do not respond to robots as entities that have the feelings that humans and animals unequivocally have.

Alternatively, as Rodogno [69] suggests, anthropomorphizing robots may be akin to our relations to characters in books, paintings, statues, and movies. For instance, we may be moved to tears by a suffering individual in a powerful movie, book, statue, or painting, and we may empathize with them, but we are (usually) under no illusion that such responses are to actual individuals who suffer or think. Although (and because) the nature of our relations to fictional characters or representations is itself philosophically controversial [70], we should not assume that relating emotionally and empathetically to fictional characters involves cognitively dubious projections onto some non-sentient (in some cases non-physical) object [71]. This explanation may not be right, but, like the above suggestions, it deserves consideration.

Darling might reply that because robots are embodied autonomous things, we will naturally respond to them much more vigorously or viscerally than to, say, inanimate statues and fictional screen characters. That may be true, but it would not show they are sufficiently different. For when we respond strongly and emotionally to robots, we may nonetheless effectively remind ourselves that "this is just a robot," just as we might think to ourselves, "don't get carried away, it's is just a movie or book."

To be fair, Darling admits that we "know" robots lack the human/animal qualities we mistakenly project onto them [9, p 223]. But if that is so, why should our responses transfer so readily from robots to humans/animals? If someone claims we are confusing appearance and reality, we can reply that we no more believe robots are sentient than we believe a 
mirage seen on a hot day is a lake. The "projections" occur, perhaps, "subconsciously" [72], at least in some sense [32], but this need not affect our awareness of the truth. These considerations surely weaken the notion of sufficient similarity and make it more plausible that, in relevant psychological ways, we will discriminate between robots and living beings.

\section{Reviving the Social Robot-Human Virtue Link?}

Although we have spent some time querying it, we shall now consider why the "link" might, after all, be plausible. We earlier noted studies showing stronger affective reactions to embodied robots that to simulations and representations [40, 41]. Darling's experiment on an insect-like robot called Hexbug revealed an aversion amongst participants to smashing it with a mallet [73]. Other experiments show people feeling apparent pity when confronted with the "torture" of Pleo the dinosaur [74]. What are we to make of this? It is not just that our responses to robots may be in some ways stronger than our responses to movie and book characters, etc. Pity for a robot is (as Darling notes) pity for a physical, autonomous, and behaving thing. Such pity is different from pity for (e.g.) book or movie characters, and in a way that comes out, for instance, in the fact that the pitying person may be motivated to refrain from damaging the robot, and also to stop others from "abusing" it.

Do responses like pity depend on mistakenly believing, consciously or subconsciously, that robots are sentient? Kant said:

If he is not to stifle his own feelings, he must practice kindness towards animals, for he who is cruel to animals becomes hard also in his dealings with men. We can judge the heart of a man by his treatment of animals [11, p 212].

Thus, the person who shows kindness to his dog whose working days are over shows good character [11]. But importantly, Kant also praises kindness to apparently nonsentient creatures:

Leibnitz put the grub he had been observing back on the tree with its leaf, lest he should be guilty of doing any harm to it. It upsets a man to destroy such a creature for no reason, and this tenderness is subsequently transferred to man [11, pp 212-213].

So, we can apparently display tenderness (pity, insensitivity, etc.) towards grubs or insects. And these responses reveal, in a certain "indirect" way, an aspect of our moral character. While Kant may have believed insects or grubs are sentient, we cannot assume he did. Moreover, many people do not regard insects as sentient, yet they still believe insects can be treated with tenderness and pity. Indeed, a child wantonly pulling wings off flies and watching them wriggle [44] is an archetype of human cruelty that need not depend on subconscious attributions of sentience. Yet we might worry that such a child, in so behaving, may be developing a more generally insensitive and unkind character towards sentient animals and humans.

Johnson and Verdicchio's claim that "animal-robot analogies fail" [15, p 294] may be questioned. They assert that suffering is a necessary condition of cruelty [15, p 298]. Yet it seems that we may, after all, intelligibly characterise the treatment of some robots as cruel even though robots are non-sentient. For insects and grubs may well lack sentience too, and yet, as Kant implies, it seems intelligible that we can not only be cruel to them, but we can also instinctively feel pity and kindness for them and sadness at their wanton destruction $[44,58]$. True, our claim here as it applies to nonliving robots may be contested, but it demands consideration.

This suggests a stronger similarity between robots and (some) animals, a similarity which may facilitate the intelligible evocation of instinctive responses like pity (and a sense of cruelty), without a need to assume mistaken conscious or subconscious projections of sentience [72]. An imaginative glimpse into the future may be helpful. Suppose that highly autonomous future robots will very compellingly be able to struggle, stagger, flee, protect themselves, play, assist others, guard and protect us, show loyalty, learn our behaviours, and attach themselves to "preferred" individuals. Some nonsentient living creatures, as we know, perform at least some of these behaviours, and they accordingly elicit pity, care, callousness, cruelty, etc. from us.

Very sophisticated robots may well elicit stronger pity than do insects, partly because they will be larger and more interactive, and partly because their behavioural repertoires will be greater. To illustrate the general point, consider a scene from the TV series The Good Place [75], in which Janet the "robot" begs the human characters to refrain from terminating her by telling them that she does not want to die. When the humans instinctively respond with sympathy and reluctance, Janet reminds them that she is not a living being with feelings, and that it is therefore irrational for them to care about her, despite her forceful protestations.

Now, instead of Janet, imagine a robot which, perhaps by means of certain non-linguistic behaviours, seeks our assistance to prevent itself from being harmed by a human "attacker," thereby eliciting our pity and care. Indeed, a recent experimental lab study found that people are reluctant to switch off a robot that audibly objects to being switched off, compared to switching off a robot that stays silent [76]. This study, which received considerable media attention, hints at a future in which we respond to robots with care when they show signs of ill-treatment.

\begin{tabular}{|l|l|l|l|l|}
\hline Journal : Large 12369 & Article No : 583 & Pages : 11 & MS Code : 583 & Dispatch : 24-8-2019 \\
\hline
\end{tabular}


Note that no irrational or mistaken projections need arise here. We may know well that the object is a non-sentient robot, but our pity (and corresponding malice etc.) will attend the intelligible recognition of its ability to struggle, flee, seek assistance, and so forth. Perhaps, then, we may say that Johnson and Verdicchio's reference [15, p 298] to "stomping on and smashing a robot to bits," as if it were any old machine, produces an oversimplified picture of what destroying these robots will be and feel like. Instead, our responses to robots may reveal a striking degree of similarity with our responses to some animals.

\section{Why the Link is Most Plausible in Relation to Children}

But still, given that we know these behaving things are robots, won't our responses sufficiently discriminate them from living beings? That is possible. We suspect, in fact, that a robot-virtue link is most plausible in relation to young children. Now, people do in fact worry that young children who are allowed to be callous rather than kind towards insects and other non-sentient animals may become callous towards humans and "higher" or sentient animals. Partly, that is because their moral responses are less reflective, are still being formed, and are more malleable. If a child sees another child callously damage a butterfly, we might react with anger and pity, and we do this to shape, in both specific and general ways, the child's humane dispositions that constitute part of human virtue.

We aim to elicit and reinforce certain instinctive and broad-and later more reflective and discriminatingresponses in those whose early moral selves are forming. As Aristotle [21] said (and many virtue ethicists would say), we must be trained from childhood to be virtuous and to have the right responses. Encouraging children to respond with kindness and pity to those robots which tend to evoke those reactions may help to nourish the psychological materials that can then be further shaped into virtuous responses to morally valuable living beings. Even where we lack conclusive scientific evidence that experiences such as wantonly harming butterflies might causally influence a child's responses to sentient beings, such a view accords with a plausible view of psychology that should not lightly be jettisoned.

Actually, there is some further empirical support to draw on here. We know that children are more susceptible than adults to social influence [77]. Vollmer et al. [78] found that while adults resisted social pressure from humanoid robots, children aged 7-9 were more likely to conform to peer pressure from a group of robots. The authors conclude that "care must be taken when designing the applications and artificial intelligence of these physically embodied machines, particularly as little is known about the long-term impact that exposure to social robots can have on the development of children and vulnerable sections of society" [78, p 4]. Kahn et al. [25] found that children under six engaged in more acts of exploration, apprehension, affection, endowing animation, and even reciprocity - but fewer acts of mistreatment - with a robot dog (AIBO) than with a stuffed toy dog. Given the affective and imaginatively social ways that children already play with inanimate dolls and simple objects [79], such findings are revealing.

In light of the above, it does now also seem plausible that children might be relevantly affected by robots that realistically simulate sentience. Darling may even be right that children (at least very young ones) will mistakenly believe that such robots are sentient. But even if children are not so easily fooled, we may still think that their responses to robots could influence the formation of virtue. Black [14] imagines future cases in which we violently harm robots with very realistic human faces. We may, he imagines, initially dismiss our automatic responses of distress as responses to "mistreatment" of mere machines; yet performing these acts repetitively could dull such visceral responses towards real people. Black's is certainly a plausible view of human psychology.

We are, it seems, already commonly interested in children's exposure to literature and film $[80,81]$. In order to shape children's moral characters, we sometimes try to cultiyate in them both general and specific responses to movie and book characters, and to deter, extinguish, or re-direct others. In so doing, we need not hold that children falsely believe that these characters really suffer, feel, etc. Nevertheless, we may want children to show sympathy in response. Perhaps we will and should encourage children to respond in similar ways to very lifelike future robots that evocatively simulate human and higher (as well as lower) animal behavior.

Moreover, we may rightly be even more concerned for their moral development when children show callous responses to lifelike robots as compared to movie characters, etc. For as we noted, such robots, unlike statues or movie characters, are autonomous physical entities, which can literally struggle, flee, protect, etc. Thus, our responses to robots are in important respects comparatively more similar to our responses to living beings. Further, some empirical evidence shows rather distinctive and strong responses to autonomous robots as compared to other non-living objects (Sect. 2).

\section{Why Responses to Nonhuman Animals May Be Most Affected}

Johnson and Verdicchio argued that social context can be crucial [54]. Although we might think that social robots will corrupt or enhance virtue, social forces may prevent 
(or exacerbate) those predicted scenarios. What social forces are relevant here? The widespread belief that humans have a unique moral standing casts some doubt not only on Kant's causal claim, but also on its robot parallel. Powerful institutions and moral vectors reinforce ethically appropriate responses to human beings. True, they may be inadequate, but they are strong.

In contrast, institutional and social forces that encourage virtuous (e.g. kind) responses to nonhuman animals are relatively weak and inconsistent. In our profoundly anthropocentric culture, some animals are loved while others are routinely treated with indifference $[22,23]$. Therefore, it is comparatively more likely that encouraging callousness to robots will promote unvirtuous responses to animals, and that encouraging caring responses to robots will promote virtuous responses to animals. Again, this seems most plausible for children. However, given that virtuous responses to animals are relatively weak, even small effects on the subsequent responses of adults who are cruel to robots may be significant.

\section{Factors that Could Strengthen a Social Robot-Human Virtue Link}

To finish, we return to the first two questions we raised in relation to the Montreal Declaration [1]. Arguably, questions 1 and 2 (Sect. 1) are connected with factors that potentially strengthen the causal link between responses to robots and (virtue-related) responses to living beings. First, imagine that some responses to social robots intrinsically constitute vice or virtue (question 2). Philosopher Rob Sparrow argues that the "rape" of lifelike robots may not only promote sexual abuse, it may itself be an expression of vice insofar as it represents the rape of a real woman [7]. Similarly, perhaps some acts of cruelty to robot animals intrinsically constitute vice. By thus establishing a greater similarity between cruelty to robots and cruelty to animals, the link with virtue vis-à-vis living animals might be strengthened.

Second, suppose we come to regard robots as have intrinsic moral standing after all (question 1) [82]. For example, we might regard responses like pity towards some of the robot behaviours we discussed, such as struggling, fleeing, seeking assistance, and exhibiting protection and "loyalty," as constituting a basis for recognising some moral patiency. In this way, robots may be seen as morally similar to some "lower" animals. ${ }^{8}$ If so, this would also potentially

8 This is, of course, contestable. Johnson and Verdicchio deny it: "Moral patients derive their moral status from their capacity to suffer and be harmed" [15, p 295]. So would many others. Some, however, deny that sentience is necessary for moral patiency (though they may not attribute intrinsic moral standing to robots or nonliving entities) [83]. strengthen the relevant link, by again establishing a greater similarity between responses to robots and responses to living beings. Such a scenario would block our ability honestly to say, to ourselves or to children, that how robots are treated is morally inconsequential because they are "just robots." The instinctive responses of some people under such conditions may not as easily discriminate between robots and animals in certain ways (even if in other ways they do).

\section{Conclusion}

In this paper, we developed several reasons for treating the claim that social robots will causally influence human virtue and vice in respect of humans and animals with some caution. However, we went on to give reasons for thinking it possible that future social robots will shape the development of virtue and vice, especially in children and especially in relation to responses towards nonhuman animals-although we also acknowledged that adults and responses to humans could also be affected. Robots may have and/or attain an ever-greater ability to strongly elicit human pity and care, as well as callousness and cruelty, because of their ability to behave at least like some lower animals. For example, social robots may variously struggle, flee, hide, play, petition assistance, etc., and their behavioural repertoires may get richer and more compelling. Acts of care or callousness towards these future robots may well encourage the development of similar responses to nonhuman animals (and possibly humans), especially in the case of children, whose moral responses are malleable and still forming, and whose ability to discriminate in their responses is relatively less than it is for adults.

Consequently, even if invoking the law in this specific context (as Darling and others do) is problematic in a liberal society, it might yet be desirable-assuming we choose to design, manufacture, and adopt such robots at all-to foster social pressures which encourage the gentle treatment of these robots (as there are, albeit weak and inconsistent, social pressures protecting non-sentient animals). Not only may this discourage morally regrettable responses to living beings, it may also furnish useful opportunities for teaching children (and perhaps adults) to develop virtues such as kindness and care for vulnerable others, human or animal.

Even if we are not virtue ethicists, we can acknowledge that virtues can help protect other humans and animals and may also be elements of personal wellbeing. It is not implausible to imagine, then, that future social robots might promote social goods and personal benefits through the inculcation of virtue-making responses. For these reasons, $\mathbf{A Q 7}_{0}$ it may be necessary to decide what kind of social robots 821 should be created and encouraged, and what kinds of social $\quad 822$

\begin{tabular}{|l|l|l|l|l|}
\hline Journal : Large 12369 & Article No: 583 & Pages : 11 & MS Code : 583 & Dispatch : 24-8-2019 \\
\hline
\end{tabular}


arrangements might be appropriate for harnessing their virtue-shaping potential.

Funding Funding was provided by Australian Research Council (AU) (Grant No. FT170100420).

\section{References}

1. Montréal Declaration for Responsible Development of Artificial Intelligence (2016) https://www.montrealdeclaration-responsibl eaicom/the-declaration

2. Levy D (2009) The ethical treatment of artificially conscious robots International. Int J Soc Robot 1(3):209-216

3. Anderson M, Anderson SL (eds) (2011) Machine ethics. Cambridge University Press, Cambridge

4. Gunkel D (2012) The machine question: critical perspectives on AI, robots, and ethics. MIT Press, Cambridge

5. Wallach W, Allen C (2009) Moral machines: teaching robots right from wrong. Oxford University Press, Oxford

6. Sullins JP (2006) When is a robot a moral agent? Int Rev Inf Ethics 6(12):23-30

7. Sparrow R (2017) Robots, rape, and representation. Int J Soc Robot 9(4):465-477

8. Cappuccio ML, Peeters A, McDonald W (2019) Sympathy for Dolores: moral consideration for robots based on virtue and recognition. Philos Technol (online), 1-23. https://www.rdcube/braeT

9. Darling K (2016) Extending legal protection to social robots: the effects of anthropomorphism, empathy, and violent behaviour towards robotic objects. In: Calo R, Froomkin AM, Kerr I (eds) Robot law. Edward Elgar, Cheltenham, pp 213-231

10. Anderson SL (2011) The unacceptability of Asimov's three laws of robotics as a basis for machine ethics. In: Anderson M, Anderson SL (eds) Machine ethics. Cambridge University Press, Cambridge, pp 285-296

11. Kant I ([1784-5]1997) Moral philosophy: Collin's lecture notes. In: Heath P, Schneewind JB (eds and trans) Lectures on ethics (Cambridge edition of the works of Immanuel Kant) Cambridge University Press, Cambridge, pp 37-222

12. Calo R (2015) Robotics and the lessons of cyberlaw. California Law Review 103:513-563

13. Coeckelbergh M (2018) Why care about robots? Empathy, moral standing, and the language of suffering. Kairos J Philos Sci 20(1):41-158

14. Black D (2019) Machines with faces: robot bodies and the problem of cruelty. Body Soc 25(2):3-27

15. Johnson DG, Verdicchio M (2018) Why robots should not be treated like animals. Ethics Inf Technol 20(4):291-301

16. Eyssel F, Kuchenbrandt D (2012) Social categorization of social robots: anthropomorphism as a function of robot group membership. Br J Soc Psychol 51(4):724-731

17. Bartneck C, Kulić D, Croft E, Zoghbi S (2009) Measurement instruments for the anthropomorphism, animacy, likeability, perceived intelligence, and perceived safety of robots. Int J Soc Robot 1(1):71-81

18. Hursthouse R (1999) On virtue ethics. Oxford University Press, Oxford

19. Swanton C (2003) Virtue ethics: a pluralistic view. Clarendon Press, Oxford

20. Ross WD (1930) The right and the good. Clarendon Press, Oxford

21. Aristotle (2003) The Nicomachean ethics. Penguin Classics, London

22. Singer P (1995) Animal liberation. Random House, London
23. Regan T (2004) The case for animal rights. University of California Press, Berkeley

24. Hursthouse R (2013) Ethics, humans and other animals: an introduction with readings. Routledge, London

25. Kahn PH, Friedman B, Perez-Granados DR, Freier NG (2006) Robotic pets in the lives of preschool children. Interact Stud 7(3):405-436

26. Dautenhahn K (2013) Human-robot interaction. In: Soegaard M, Dam RF (eds) The encyclopedia of human-computer interaction, 2nd edn. The Interaction Design Foundation, Aarhus

27. Mori M (1970) The uncanny valley. Energy 7(4):33-35

28. Coghlan S, Waycott J, Neve BB, Vetere F (2018) Using robot pets instead of companion animals for older people: a case of 'reinventing the wheel'? In: Proceedings of the 30th Australian conference on computer-human interaction, pp 172-183

29. Sandry E (2015) Re-evaluating the form and communication of $\mathbf{A Q 9}^{\mathbf{8 9}}$ social robots. Int J Soc Robot 7(3):335-346

30. Breazeal C (2003) Toward sociable robots. Robot Auton Syst 42(3-4):167-175

31. Melson GF, Kahn Jr PH, Beck AM, Friedman B, Roberts T, Garrett E (2005) Robots as dogs? Children's interactions with the robotic dog AIBO and a live Australian shepherd. In: CHI'05 extended abstracts on human factors in computing systems. ACM, pp 1649-1652

32. Friedman B, Kahn Jr PH, Hagman J (2003) Hardware companions? What online AIBO discussion forums reveal about the human-robotic relationship. In: Proceedings of the SIGCHI conference on human factors in computing systems. ACM, pp $273-280$

33. Reeves B, Nass CI (1996) The media equation: how people treat computers, television, and new media like real people and places. Cambridge University Press, Cambridge

34. Whitby B (2008) Sometimes it's hard to be a robot: a call for action on the ethics of abusing artificial agents. Interact Comput 20:338-341

35. de Graaf MM (2016) An ethical evaluation of human-robot relationships. Int J Soc Robot 8(4):589-598

36. Turkle $\mathrm{S}$ (2017) Alone together: why we expect more from technology and less from each other. Hachette, New York

37. Hamill J (2017) Office mounts touching memorial for security robot that drowned itself. New York Post https://www.nypos tcom/2017/07/20/office-mounts-touching-memorial-for-secur ity-robot-that-drowned-itself/

38. Every time Boston Dynamics has abused a robot (2017) YouTube. https://youtu.be/4PaTWufUqqU

39. Sparrow R (2016) Kicking a robot dog. In: 2016 11th ACM/IEEE international conference on human-robot interaction, pp 229-229

40. Seo SH, Geiskkovitch D, Nakane M, King C, Young, JE (2015) Poor thing! Would you feel sorry for a simulated robot? A comparison of empathy toward a physical and a simulated robot. In: 2015 10th ACM/IEEE international conference on human-robot interaction, pp 125-132

41. Bartneck $\mathrm{C}, \mathrm{Hu} \mathbf{J}$ (2008) Exploring the abuse of robots. Interact Stud 9(3):415-433

42. Carpenter J (2016) Culture and human-robot interaction in militarized spaces: a war story. The Atlantic. https://www.theat lanticcom/technology/archive/2013/09/funerals-for-fallen-robot s/279861/

43. Nomura T, Kanda T, Kidokoro H, Suehiro Y, Yamada S (2016) Why do children abuse robots? Interact Stud 17(3):347-369

44. Dadds MR, Turner CM, McAloon J (2002) Developmental links between cruelty to animals and human violence. Aust N Z J Criminol 35(3):363-382

45. Coeckelbergh M (2011) Humans, animals, and robots: a phenomenological approach to human-robot relations. Int J Soc Robot 3(2):197-204 
46. Duffy BR (2003) Anthropomorphism and the social robot. Robot Auton Syst 42(3/4):177

47. Damiano L, Dumouchel P (2018) Anthropomorphism in humanrobot co-evolution. Front Psychol. https://doi.org/10.3389/fpsyg .2018 .00468

48. Hegel F, Krach S, Kircher T, Wrede B, Sagerer G (2008) Understanding social robots: a user study on anthropomorphism. In: ROMAN 2008-the 17th IEEE international symposium on robot and human interactive communication, pp 574-579

49. Anderson CA, Bushman BJ (2001) Effects of violent video games on aggressive behavior, aggressive cognition, aggressive affect, physiological arousal, and prosocial behavior: a meta-analytic review of the scientific literature. Psychol Sci 12(5):353-359

50. Ferguson CJ (2015) Does movie or video game violence predict societal violence? It depends on what you look at and when. J Commun 65(1):193-212

51. Calverley D (2006) Android science and animal rights, does an analogy exist? Connect Sci 18(4):403-417

52. Hogan K (2017) Is the machine question the same question as the animal question? Ethics Inf Technol 19:29-38

53. Richards E, Signal T, Taylor N (2013) A different cut? Comparing attitudes toward animals and propensity for aggression within two primary industry cohorts-farmers and meatworkers. Soc Anim 21(4):395-413

54. Johnson DG, Verdicchio M (2017) AI anxiety. J Assoc Inf Sci Technol 68(9):2267-2270

55. Dowsett A, Jackson M (2019) The effect of violence and competition within video games on aggression. Comput Hum Behav 99:22-27

56. Ferguson CJ, Colwell J (2018) A meaner, more callous digital world for youth? The relationship between violent digital games, motivation, bullying, and civic behavior among children. Psychol Pop Med Cult 7(3):202

57. Shibuya A, Sakamoto A, Ihori N, Yukawa S (2008) The effects of the presence and contexts of video game violence on children: a longitudinal study in Japan. Simul Gaming 39(4):528-539

58. Arluke A (2002) Animal abuse as dirty play. Symb Interact 25(4):405-430

59. Gullone E (2012) Animal cruelty, antisocial behaviour, and aggression: more than a link. Palgrave Macmillan, Basingstoke

60. Kant I ([1785](1998) Groundwork of the metaphysics of morals. Gregor MJ (trans). Cambridge University Press, Cambridge

61. O’Neill O (1998) June) Kant on duties regarding nonrational nature. Aristot Soc Suppl 71(1):211-228

62. Rozuel C (2011) The moral threat of compartmentalization: self, roles and responsibility. J Bus Ethics 102(4):685-697

63. Monte CF (1997) Beneath the mask: an introduction to theories of personality, 6th edn. Harcourt Brace, Fort Worth

64. Fink J (2012). Anthropomorphism and human likeness in the design of robots and human-robot interaction. In: International conference on social robotics. Springer, Berlin, Heidelberg, pp 199-208

65. Airenti G (2015) The cognitive bases of anthropomorphism: from relatedness to empathy. Int J Soc Robot 7(1):117-127
66. Turkle S (2007) Authenticity in the age of digital companions. Interact Stud 8:501-517. https://doi.org/10.1075/is.8.3.11tur

67. Złotowski J, Proudfoot D, Yogeeswaran K, Bartneck C (2015) Anthropomorphism: opportunities and challenges in human-robot interaction. Int J Soc Robot 7(3):347-360

68. Melson GF, Kahn PH Jr, Beck A, Friedman B, Roberts T, Garrett E, Gill BT (2009) Children's behavior toward and understanding of robotic and living dogs. J Appl Dev Psychol 30(2):92-102

69. Rodogno R (2016) Social robots, fiction, and sentimentality. Ethics Inf Technol 18(4):257-268

70. Lamarque P (1981) How can we fear and pity fictions? Br J Aesthet 21(4):291-304

71. Schneider S (2006) The paradox of fiction. The internet encyclopedia of philosophy. http://www.ieputmedu/f/fict-parhtm

72. Sparrow R (2002) The march of the robot dogs. Ethics Inf Technol 4(4):305-318

73. Darling K, Nandy P, Breazeal C (2015) Empathic concern and the effect of stories in human-robot interaction. In: 2015 24th IEEE international symposium on robot and human interactive communication (RO-MAN), pp 770-775

74. Rosenthal-von der Pütten AM, Krämer NC, Hoffmann L, Sobieraj S, Eimler SC (2013) An experimental study on emotional reactions towards a robot. Int J Soc Robot 5(1):17-34

75. The Good Place (2018) Chapter 7: The eternal shriek. Netflix, Scotts Valley

76. Horstmann AC, Bock N, Linhuber E, Szczuka JM, Straßmann C, Krämer NC (2018) Do a robot's social skills and its objection discourage interactants from switching the robot off? PLoS ONE 13(7): 0201581

77. Damon W, Lerner RM, Eisenberg N (eds) (2006) Handbook of child psychology, social, emotional, and personality development, vol 3. Wiley, Hoboken

78. Vollmer AL, Read R, Trippas D, Belpaeme T (2018) Children conform, adults resist: a robot group induced peer pressure on normative social conformity. Sci Robot. https://doi.org/10.1126/ scirobotics.aat7111

79. Goodliff G, Canning N, Parry J, Miller L (eds) (2017) Young children's play and creativity: multiple voices. Taylor \& Francis, Abingdon

80. Carr D, Harrison T (2015) Educating character through stories. Imprint Academic, Exeter

81. Almerico GM (2014) Building character through literacy with children's literature. Res Higher Educ J 26

82. Coeckelbergh M (2010) Moral appearances: emotions, robots, and human morality. Ethics Inf Technol 12(3):235-241

83. Taylor PW (2011) Respect for nature: a theory of environmental ethics. Princeton University Press, Princeton

Publisher's Note Springer Nature remains neutral with regard to jurisdictional claims in published maps and institutional affiliations.

\begin{tabular}{|l|l|l|l|l|}
\hline Journal : Large 12369 & Article No: 583 & Pages : 11 & MS Code : 583 & Dispatch : 24-8-2019 \\
\hline
\end{tabular}

